\title{
The new coronavirus (COVID-19) and the social impact on the elderly population in Brazil
}

\begin{abstract}
Coronavirus is a family of viruses that cause respiratory infections. The new coronavirus agent was discovered on 12/31/19 after cases registered in China. It causes the disease called coronavirus (COVID-19). The first human coronaviruses were isolated for the first time in 1937. However, it was in 1965 that the virus was described as coronavirus, due to the profile under microscopy, looking like a crown. Most people become infected with common coronaviruses throughout their lives, with young children being more likely to become infected with the most common type of virus. The most common coronaviruses that infect humans are alpha coronavirus 229E and NL63 and beta coronavirus OC43, HKU1.
\end{abstract}

Volume 5 Issue 2 - 2020

Souza MC, Luiz Amaro do Nascimento Neto, Lucas Afonso Barbosa Saraiva,Caio Vinicius Afonso Barbosa Saraiva,Ariosto Afonso de Morais, Thais Monara Bezerra Ramos, Júlia Rafaelly de Matos Barbosa Jordão Nurses and Doctors (Independent Intellectual Researchers), Individual Academic League, Medicine Clinic, Federal University of Pernambuco (UFPE), Brazil

Correspondence: Souza MC, Medicine Clinic, Federal University of Pernambuco (UFPE), Brazil, Tel 8198I255845, Email Article_ufpe@hotmail.com

Received: March 22, 2020 | Published: April 07, 2020

\section{Contextualization}

The new coronavirus has been presented by health authorities as not very lethal, but this situation changes when only older patients are taken into account.

A study by the Center for Disease Control and Prevention in China based on data collected until February 11 found that, among 44,672 confirmed cases, there were 1,023 deaths.

This means that, until that moment, the new coronavirus had a fatality rate of $2.3 \%$ - an index that is now $3.4 \%$, according to the most recent official data: 2,801 deaths were recorded among 82,168 confirmed cases, until the time of publication of this report.

What happens now that Brazil has the first confirmed case of coronavirus

Why is a Brazilian with coronavirus going to quarantine at home?

But, among the older patients evaluated in the Chinese study, the lethality of the new coronavirus is not only higher than the average for the general population, but this rate progresses according to the age group.

Among those infected between the ages of 60 and 69, 3.6\% died. The lethality rate was $8 \%$ for those between 70 and 79 years old and $15 \%$ for patients over 80 years old.

Infectologist Kleber Luz, professor at the Institute of Tropical Medicine at the Federal University of Rio Grande do Norte (UFRN), explains that the elderly are more vulnerable because, from the age of 60 , our immune system suffers a deterioration due to aging, a phenomenon called immunosenescence.

To protect yourself, most of the recommendations for the elderly are the same as those of the general population, such as washing your hands with soap after using the bathroom, when you get home and before handling food.

It is also important to avoid touching your mouth, nose or eyes if you are in a public environment or in places of large crowds, because the virus is transmitted by air and by contact with respiratory secretions. And keep the environments clean and sanitize surfaces, furniture and cell phones with disinfectant products.

However, there is some advice aimed especially at the elderly. "People are often worried about the coronavirus and forget about other diseases, so it is important to keep these diseases under control, because that way there is less chance of them being decompensated by a new infection and leading the patient to death", says Luz .

Spilki also recommends maintaining a good diet and doing physical activity regularly to slow the deterioration of the immune system, in addition to checking that all vaccines are up to date, especially that of the flu.

With the arrival of winter, the virus that causes this disease, influenza, circulates more easily, and cases of influenza multiply.

"Catching the coronavirus and having the flu at the same time can generate a cross-infection, causing an effect that potentiates both diseases and creates a double challenge for the immune system."

But, according to Health Minister Luiz Henrique Mandetta, people should not rush to health centers or the private health network now to get vaccinated against the flu.

It is necessary to wait for the new batch of vaccines for influenza that is being developed, to be completed and then offered to the population.

"The flu vaccines that are still in stock are from last year and have no efficacy on the viruses that will be circulating in our winter, which are new. For them, it will be necessary to take the vaccine that will be distributed between the last half of March and the beginning of April, "said Mandetta

As a result, our bodies lose the ability to respond in the best possible way to an infection. This means that it can react not only insufficiently and fail to fight the disease caused by the virus but also have an exaggerated response, which harms the body. 
"An impaired immune system cannot modulate the response and generates uncontrolled inflammation, which favors a disorganization of the pulmonary microenvironment, where bacteria live in harmony with the organism and, in the face of inflammation, they can proliferate", says Luz.

In addition, the cells of the immune system that should only kill infected cells end up also reaching those that are healthy, causing more injuries, says Fernando Spilki, president of the Brazilian Society of Virology.

"It is not surprising that this new virus causes this, because it is already established in the medical literature that this imbalance of the immune system occurs in the elderly with the flu and other respiratory infections," says Spilki.

At the same time, the elderly generally have other illnesses, such as diabetes, high blood pressure or cardiovascular problems. When the coronavirus causes inflammation in the body, it worsens other diseases.
"An elderly person will never have only a coronavirus infection, but one or two other diseases. When this occurs, these other diseases decompose. The heart stops pumping right blood, there is pulmonary edema or renal failure", says Luz.

"This coronavirus has a small capacity to produce a serious disease, so to be able to kill it is necessary that other factors are involved."

\section{Acknowledgments}

None.

\section{Conflicts of interest}

The authors declare have no conflict of interest about the publicationof this paper. 